\title{
The Benefits of Enterprise Architecture for Library Technology Management: An Exploratory Case Study
}

Sam Searle

\section{ABSTRACT}

This case study describes how librarians and enterprise architects at an Australian university worked together to document key components of the Library's "as-is" enterprise architecture (EA). The article covers the rationale for conducting this activity, how work was scoped, the processes used, and the outputs delivered. The author discusses the short-term benefits of undertaking this work, with practical examples of how outputs from this process are being used to better plan future library system replacements, upgrades, and enhancements. Longer-term benefits may also accrue in the future as the results of this architecture work inform the Library's IT planning and strategic procurement. This article has implications for practice for library technology specialists as it validates views from other practitioners on the benefits for libraries in adopting enterprise architecture methods and for librarians in working alongside enterprise architects within their organizations.

\section{INTRODUCTION}

Griffith University is a large comprehensive university with multiple campuses located across the South East Queensland region in Australia. Library and information technology operations are highly converged and from 1989-2017 were offered within a single Division of Information Services. Scalable, sustainable, and cost-effective IT is seen as a key strategic enabler of the University's core business in education and research. "Information Management and Integration" and "Foundation Technology" are two of four key areas outlined in the Griffith Digital Strategy 2020, which highlights enterprise-wide decision-making and proactive moves to take advantage of As-a-Service models for delivering applications. ${ }^{1}$

From late 2016 through to early 2018, Library and Learning Services ("the Library") and IT Architecture and Strategy (ITAS) worked iteratively to document key components of the Library's "as-is" enterprise architecture (EA). Around fifty staff members have participated in the process at different points. The process has been very positive for all involved and has led to a number of benefits for the library in terms of improved planning, decision-making, and strategic communication.

As Manager, Library Technology Services, the author was well placed to act as a participant-asobserver with the objective of sharing these experiences with other library practitioners. The author actively participated in the processes described here and has been able to informally discuss the benefits of this work with the architects and some of the library staff members who were most involved.

Sam Searle (samantha.searle@griffith.edu.au) is Manager, Library Technology Services, Griffith University, Brisbane, Australia. 


\section{LITERATURE REVIEW}

Enterprise architecture (EA) emerged over twenty years ago and is now a well-established IT discipline. Like other disciplines such as project management and change management, there are a number of best practice frameworks in common use, including The Open Group Architecture Framework (TOGAF). ${ }^{2}$ A global federation of member professional associations has been in place since 2011, with aims including the formalization of standards and promotion of the value of EA. ${ }^{3}$ Educational qualifications, certifications, and professional development pathways for enterprise architects are available within universities and the private training sector.

According to the international higher education technology association EDUCAUSE, EA is relatively new within universities but is growing in importance. As a set of practices, "EA provides an overarching strategic and design perspective on IT activities, clarifying how systems, services, and data flows work together in support of business processes and institutional mission." ${ }^{4}$ Yet despite this growing interest in our parent organizations, individual academic libraries applying EA principles and methods are notably absent from the scholarly literature and library practitioner information sharing channels.

The fullest account to date of the experience and impacts of enterprise architecture practice in a library context is a case study from the Canada Institute for Scientific and Technical Information (CISTI). At the time of the case study's writing in 2008, CISTI was already well underway in its adoption of EA methods in an effort to address the challenges of "legacy, isolated, duplicated, and ineffective information systems" and to "reduce complexity, to encourage and enable collaborations, and, finally, to rein in the beast of technology." 5 The author of this case study concludes that while getting started in EA was complex and resource-intensive, this was more than justified at CISTI by the improvements in technology capability, strategic planning, and services to library users.

Broader whole-of-government agendas are a driver for EA adoption in non-university research libraries. The National Library of Finland's EA efforts were guided by a National Information Society Policy and the EA architecture design method for Finnish government. ${ }^{6}$ A 2009 review of the IT infrastructure at the U.S. Library of Congress (LC) argued LC was lagging behind other federal agencies in adoption of government-recommended EA frameworks. The impact of this included: inadequate linking of IT to the LC mission; potential system interoperability problems; difficulties assessing and managing the impact of changes; poor management of IT security; and technical risk due to non-adherence to industry standards and lack of future planning. ${ }^{7} \mathrm{~A}$ followup review in 2015 noted that LC had since developed an architecture, but that it had still fallen short by not gathering data from management and validating the work with stakeholders. ${ }^{8}$

There is little discussion in the literature about the EA process as a collaborative effort. In their 2016 discussion of emerging roles for librarians, Parker and McKay proposed EA as a new area for librarians themselves to consider moving into, rather than as a source of productive partnerships. ${ }^{9}$ They argued that there are many similarities in the skillsets and practices of enterprise architects and information professionals (in particular, systems librarians and corporate information managers). Areas of crossover identified included: managing risks, for example, related to intellectual property and data retention; structured and standardized approaches to (meta)data and information; technical skills such as systems analysis, database design and vendor management; and understanding and application of information standards and internal 
information flows. While not a research library, within a broader information management context State Archives and Records NSW has promoted the benefits to records managers of working with enterprise architects, including improved program visibility, strategic assistance with business case development, and the embedding of recordkeeping requirements within the organization's overall enterprise architecture. ${ }^{10}$

\section{GETTING STARTED: CONTEXT AND PLANNING}

\section{Library Technology Services Context}

In 2015-16, the awareness of enterprise and solution architecture expanded significantly within Griffith University's Library Technology Services (LTS) team. In 2015, some members of the team participated in activities led by external consultants to document Griffith's overall enterprise architecture at a high level. In 2016, the author became a member of the University's Solution Architecture Board (SAB). LTS submitted several smaller solution architectures to this group for discussion and approval, and team members found this process useful in identifying alternative ways to do things that we may not have otherwise considered.

As a small team looking after a portfolio of high-use applications, LTS was seeking to align itself as much as possible with university-wide IT governance and strategy. These broader approaches included aggressively seeking to move services to cloud hosting, standardizing methods for transferring data between systems, complying with emerging requirements for greater IT security, and participating in large-scale disaster recovery planning exercises.

The author also needed to improve communication with senior IT stakeholders. There was little understanding outside of the Library of the scale and complexity involved in delivering online library services to a community of over 50,000 people. In a resource-scarce environment, it was increasingly important to make business cases not just in formal project documents but also opportunistically in less formal situations (the "elevator pitch").

Existing systems were definitely hindering the Library in making progress toward an improved online student experience and more efficient usage of staff resources. A complex ecosystem of more than a dozen library applications had developed over time. The Library had selected these at different times based on requirements for specific library functions rather than alignment with an overall architectural strategy. Our situation mirrored that described at CISTI: "a complex and 'siloed' legacy infrastructure with significant vendor lock-in" combined with "reactionary" projects that "extended or redesigned [existing infrastructure] to meet purported needs, without consideration for the complexity that was being added to overcomplicated systems."11 Complex data flows between local systems and third-party providers that were critical to library services were not always well-documented.

While LTS staff members were extremely experienced, much of their knowledge was tacit. As in many libraries, staff could be observed sharing in informal, organic ways focused on the tasks at hand, but less effort was spent on capturing knowledge systematically. Building a more explicit shared understanding about the Library's application portfolio would help address risks associated with staff succession. Improved internal documentation would also address emerging requirements for team members to both develop their own understanding in new areas (upskilling) as well as become more flexible in terms of taking up broader roles and responsibilities across the team (cross-skilling). 
There was also a sense that the time was right to take stock and evaluate the current state of affairs before embarking on any major changes. The team was supporting several applications, including the library management system and the interlibrary loans system, that were end-of-life. We needed to make decisions, and these needed to not only address our current issues but also provide a firm platform for the future.

It was in this context that in 2016 Library Technology Services approached the Information Technology Architecture and Solutions group for assistance.

\section{Information Technology Architecture and Solutions Context}

In 2014, Griffith University embarked on a new approach to enterprise architecture. The Chief Technology Officer was given a mandate by the senior leadership of the University to ensure that IT architecture was managed within an architecture governance framework, and the Information Services EA team was tasked with developing and maintaining an EA and providing services to support the development of solution architectures for projects and operational activities. Two new boards were established to provide governance: The Information and Technology Architecture Board (ITAB) would control architectural standards and business technology roadmaps, while the Solution Architecture Board (SAB) would "support the development and implementation of solution architecture that is effective, sustainable and consistent with architectural standards and approaches." Project teams and operational areas were explicitly given responsibility to engage with these boards when undertaking the procurement and implementation of IT systems. Sets of architectural, information, and integration principles were developed, which promoted integration mechanisms that minimized business impact and were future-proof, loosely coupled, reusable, and shared services. ${ }^{12}$

Our enterprise architects saw their primary role as maximizing the value of the University's total investment in IT by promoting standards and frameworks that could potentially improve consistency and reduce duplication across the whole organization. In order to do this, they would need to work with and through other business units. From the architects' perspective, a collaboration with the Library offered an opportunity to exercise skillsets and frameworks that were in place but still relatively new. Griffith was still maturing in this area and attempting to move from the hiring of consultants as the norm to building more internal capability. Working with the Library would be a good learning experience for a junior architect, who was on a temporary work placement from another part of Information Services as a professional development opportunity. She could build her skills in a friendly environment before embarking on other engagements with potentially less open client groups.

\section{Determining Scope in a Statement of Architecture Work}

Once the two teams had decided that the process could have benefits on both sides, the next step was to jointly develop a Statement of Architecture Work outlining what the process would include and how we would work together. A formal document was eventually endorsed at the Director level, but prior to that, the librarians and the architects had a number of useful informal conversations in which we discussed our expectations, as well as the amount of time that we could reasonably contribute to the process.

In developing the Statement of Work, the two teams agreed to focus on the current "as-is" environment and on assessment of the maturity of the applications already in use (see figure 1). This would help us immediately with developing business cases and roadmaps, without 
necessarily committing either team to the much greater effort required to identify an ideal "to-be" (i.e., future) state to work towards.

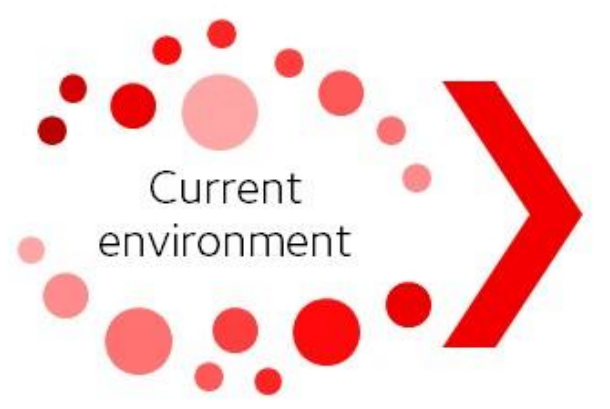

$$
\begin{gathered}
\text { Maturity } \\
\text { assessment }
\end{gathered}
$$
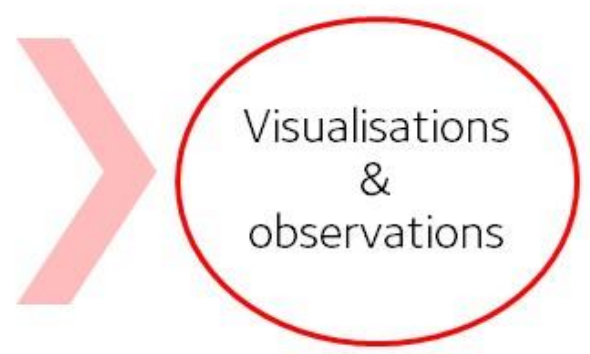

- Key stakeholders

- Library data model

- Library application portfolio

- Manual \& automated data integration
- Business criticality

- Functional coverage

- Information quality

- Performance

- Time to market

- IT standards compliance

- Supportability
- Application data flows

- Application strategies

- Data silos

- Business case recommendations

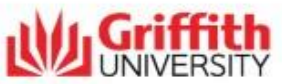

Figure 1. Overview of the Architecture Statement of Work. Full size version available at https://doi.org/10.6084/m9.figshare.6667427.

The Open Group Architecture Framework (TOGAF) supports the development of enterprise architectures through four subdomains: Business Architecture, Data Architecture, Application Architecture, and Technology Architecture. ${ }^{13}$ The work that we decided to pursue maps to two of these areas: Data Architecture, which "describes the structure of an organization's logical and physical data assets and data management resources;" and Application Architecture, which "provides a blueprint for the individual applications to be deployed, their interactions, and their relationships to the core business processes of the organization."

\section{ENTERPRISE ARCHITECTURE PROCESS AND OUTPUTS}

Once the Architecture Statement of Work had been agreed on, the two teams embarked on the process of working together over an extended period. While the lapsed time from approval of the Statement of Work through to endorsement of the architecture outputs by the Solution Architecture Board was approximately fourteen months, the bulk of the work was undertaken within the first six months. Following an intense period of information gathering involving large numbers of staff, a smaller subset of people then worked iteratively to refine the outputs for final approval. Several times architecture activities had to be placed on hold in favor of essential ongoing operational work and higher priority projects, such as a major upgrade of the institutional repository. The process involved four main activities which are described in more detail in following sections. 


\section{Data Asset and Application Inventory}

The first activity consisted of a series of three workshops to review information held about library systems in the EA management system, Orbus Software's iServer. This is the tool used by the Griffith EA team to develop and store architectural models, and to produce artifacts such as architecture diagrams (in Microsoft Visio format) and documentation (in Microsoft Word, Excel, and PowerPoint formats). ${ }^{14}$

The architects guided a group of librarians who use and support library systems through a process of mapping the types of data held against an existing list of enterprise data entities. In this context, a data entity is a grouping of data elements that is discrete and meaningful within a particular business context. For library staff, meaningful data entities included all the data relating to a Person, to items and metadata within a library Collection, and to particular business processes such as Purchasing.

We also identified the systems into which data were entered (System of Entry), the systems that were considered the "source of truth" (System of Record), and the systems that made use of data downstream from those systems of record (Reference Systems).

The main output of this process was a workbook (figure 2) showing a range of relationships: between systems and data entities; between internal systems; and between internal systems and external systems.

The first two columns in the worksheet contain a list of all the data entities and sub-entities stored in library systems (as expressed in the enterprise architecture). Along the top of the worksheet is a list of all the products in our portfolio along with a range of systems they are integrated with. Each of the orange arrows in this spreadsheet represents the flow of data from one system to another. The workbook in this raw form is definitely messy and the data within it is not really meant to be widely consumed in this format. The workbook's main role is as the data source for the application communication diagram that is described in a later section.

As a result of this data asset inventory, the management system used by our architects now contains a far more comprehensive and up-to-date view of the Library's architectural components than before:

- The data entities better reflect library content. For example, while iServer already had a Collection Item data entity, we were able to add new data entity subtypes for Bibliographic Records, Authority Records, and Holdings Records.

- Library systems are now captured in ways that make more sense to us. Workshopping with the architects led to the breakdown of several applications into more granular architectural components. For example, the library management system is now represented not just as a single system, but rather as a set of interconnected modules that support different business functions, such as cataloguing and circulation. Similarly, our reading lists solution was broken down into its two main components: one for managing reading lists and one for managing digitized content. This granularity has enabled us to build a clearer picture of how systems (and modules within systems) interface with each other. 


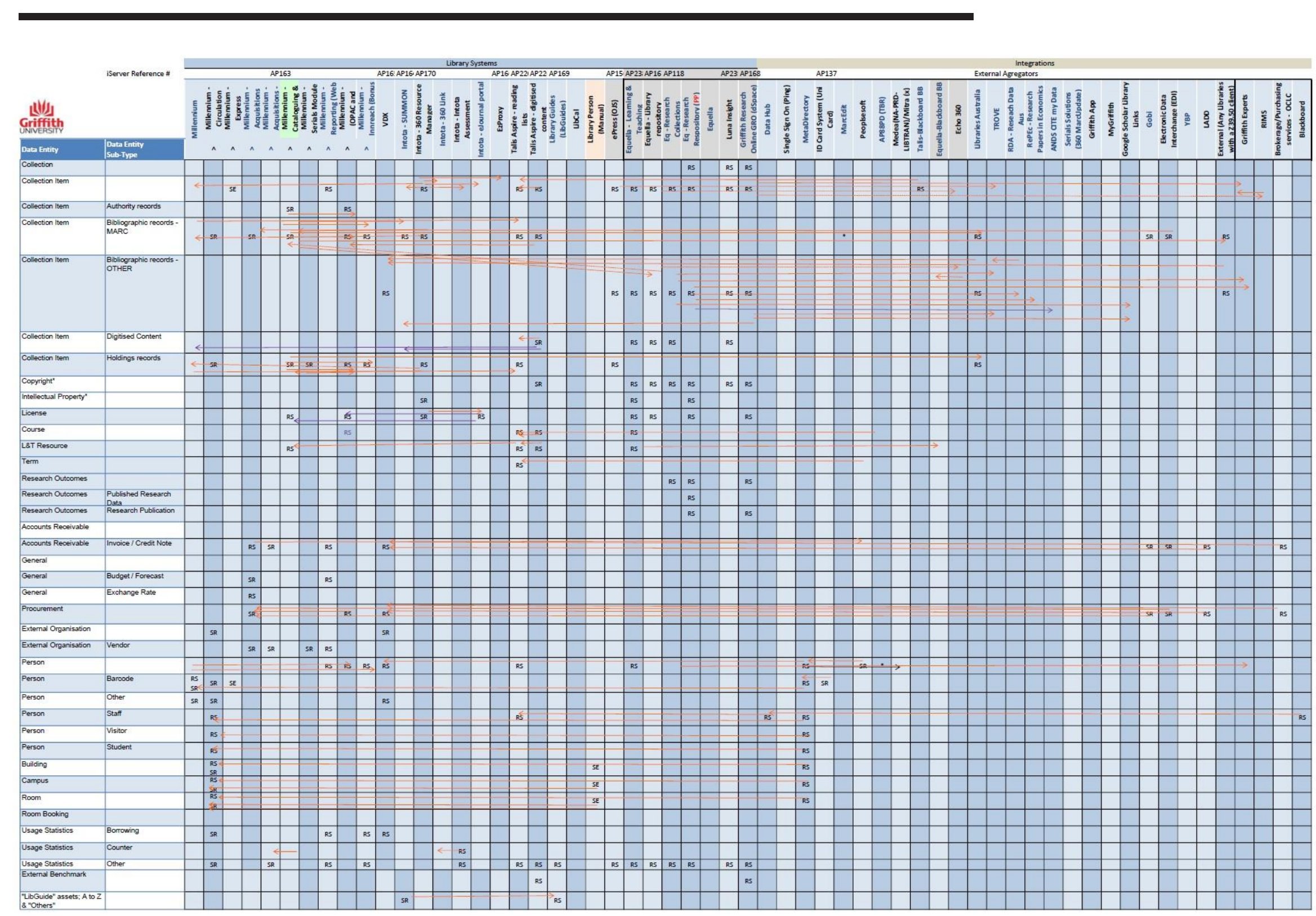

Figure 2. Part of the data asset and application inventory worksheet. Full size version available at https://doi.org/10.6084/m9.figshare.6667430. 
- The wide range of technical interfaces we have with third parties, such as publishers and other libraries, is now explicitly expressed. Feedback from the architects suggested that the Library was very unusual compared to other parts of the organization in terms of the number of critical external systems and services that we use as part of our service provision. Previously iServer did not contain a full picture of these critical services, including:

○ the web-based purchasing tools that we use to interact with publishers, such as EBSCO's GOBI; ${ }^{15}$

- the Library Links program that we use to provide easier access to scholarly content via Google Scholar; ${ }^{16}$ and

- various harvesting processes that enable us to share metadata with content aggregators, such as the National Library of Australia's Trove service and the Australian National Data Service's Research Data Australia portal. ${ }^{17}$

\section{Application Maturity Survey}

The second activity was an application maturity assessment. This involved forty-four staff members from all areas of the Library with different viewpoints (technical, non-technical, and management) answering a series of questions in a spreadsheet format.

The survey contained questions about:

- how often a system was used;

- how easy it was to use;

- how well it supported the business processes that person carried out;

- how well it performed, for example, in terms of response times;

- how quickly changes/enhancements were implemented in the product;

- how easily the system could be integrated with other systems;

- the level of compliance with industry standards; and

- overall supportability (including vendor support).

As different respondents were assigned multiple systems depending on their level of support and/or use, the final overall number of responses to the survey was 144 responses relating to eleven different systems.

The outputs of this process were a summary table and a series of four graphs.

The summary table (see figure 3) presents aggregated scores on a scale of one (low) to five (high) for each application as well as recommended technical and management strategies.

It is interesting, and somewhat disheartening, to note that scores for the business criticality of the applications are generally much higher than the scores for fitness. There is also some variation in the strategies required; some systems need to be replaced, but there are others where the issues seem to be less technical. The third row of the table shows a product that is scored as highly business-critical and perfectly suited to the job from a technical perspective, yet the product still scores much more poorly for business fit, which could indicate that something has gone wrong in the way that this product has been implemented. 


\begin{tabular}{|c|c|c|c|c|c|c|}
\hline Name & $\begin{array}{l}\text { Business } \\
\text { Criticality }\end{array}$ & $\begin{array}{l}\text { Suitability } \\
\text { (Fit for } \\
\text { purpose) }\end{array}$ & $\begin{array}{c}\text { Business } \\
\text { Fit }\end{array}$ & $\begin{array}{c}\text { Technical } \\
\text { Fit }\end{array}$ & Portfolio Quadrant & Management Strategy \\
\hline \multirow{14}{*}{ Product names redacted } & 3.7 & 2.7 & 2.7 & 3.0 & Mitigate & Replace \\
\hline & 5 & 3.7 & 3.7 & 3.8 & Optimise & Optimise \\
\hline & 5 & 2.9 & 2.9 & 5.0 & Mitigate & Implementation Review \\
\hline & 4.7 & 3.6 & 3.6 & 3.6 & Optimise & Optimise \\
\hline & 4 & 2.2 & 2.2 & 3.4 & Mitigate & Implementation Review \\
\hline & 4.4 & 2.6 & 2.6 & 3.3 & Mitigate & Implementation Review \\
\hline & 4.7 & 3.8 & 3.8 & 4.2 & Optimise & Optimise \\
\hline & 4.8 & 3.5 & 3.5 & 3.9 & Optimise & Optimise \\
\hline & 4.7 & 2.6 & 2.6 & 2.7 & Mitigate & Replace \\
\hline & 4.8 & 2.9 & 2.9 & 3.0 & Mitigate & Replace \\
\hline & 4.4 & 2.5 & 2.5 & 2.7 & Mitigate & Replace \\
\hline & 4.3 & 2.5 & 2.5 & 2.7 & Mitigate & Replace \\
\hline & 5 & 2.8 & 2.8 & 3.1 & Mitigate & Implementation Review \\
\hline & 4.5 & 2.7 & 2.7 & 3.4 & Mitigate & Implementation Review \\
\hline
\end{tabular}

Figure 3. Table summarizing the results of the application maturity assessment [product names redacted]. Applications are rated on a scale of one to five, and one of four management strategies (Technology Refresh—not shown here, Optimise, Implementation Review, or Replace) is recommended. Full size version available at https://doi.org/10.6084/m9.figshare.6667433.

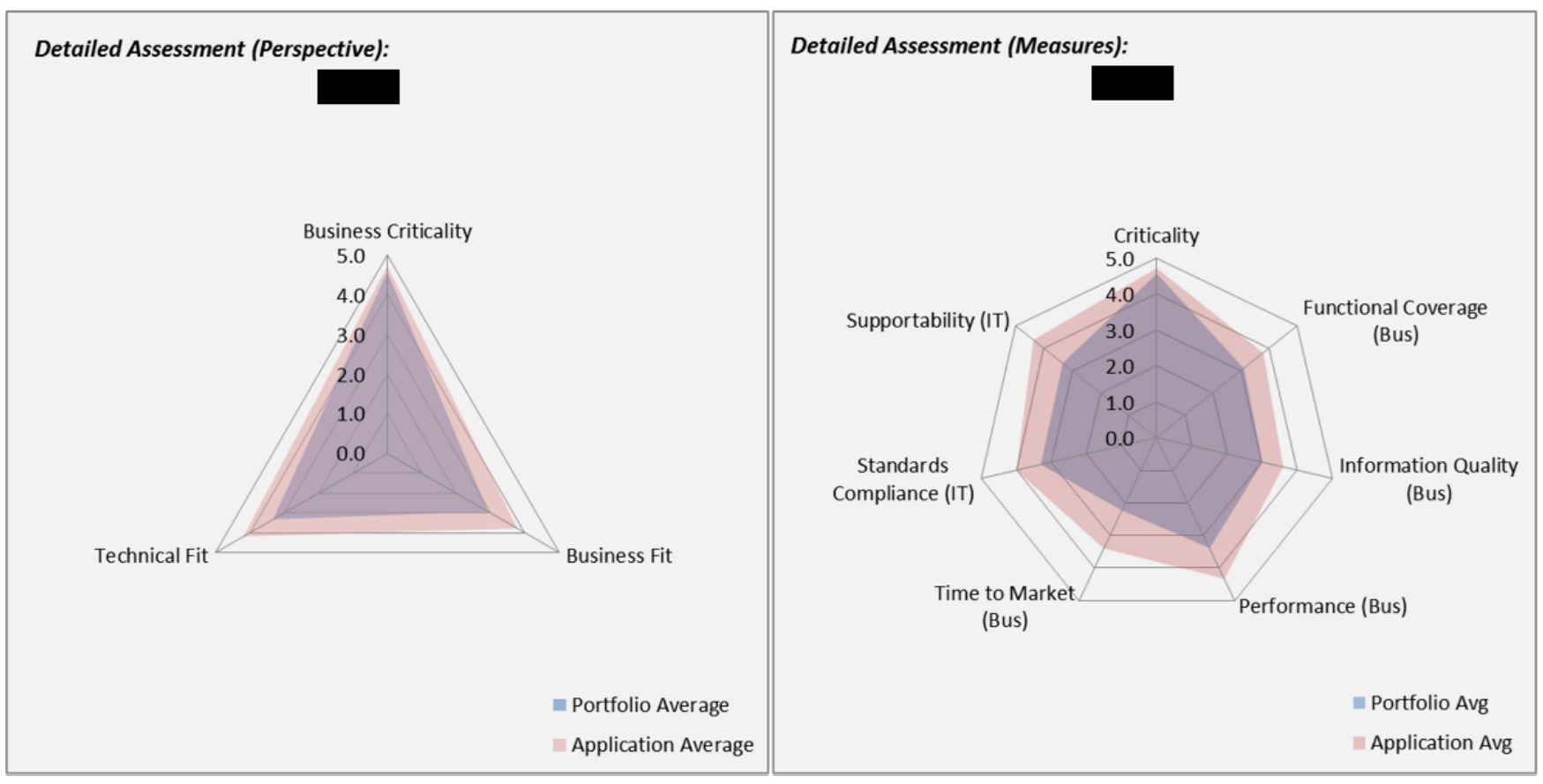

Figure 4. Two of the four graph types produced from the application maturity survey results, for a product [name redacted] that is performing well. Full size version available at https://doi.org/10.6084/m9.figshare.6667436.

Figures 4 and 5 show the four graph types produced automatically from the survey results. On the left in figure 4 is a view displaying the Business Criticality, Business Fit, and Technical Fit for an individual application (shown in pink) as compared to the overall portfolio (shown in blue). On the right is a graph showing scores for the range of measures covered by the survey. This 
particular product is doing well; technical and business fit are high in the graph on the left, and most measures are above average in the graph on the right.

Figure 5 shows the remaining two graphs for the same product. The graph on the left plots the scores for Business Criticality and Application Suitability (fitness for purpose) to produce a recommended technical strategy. The graph on the right plots the scores for Business Fit and Technical Fit to produce a recommended management strategy. In both graphs, it is possible to see how the specific application is performing (the red square) compared to the portfolio overall (the blue diamond). Placement within the quadrant with the green Optimize label is preferred, as in this case.

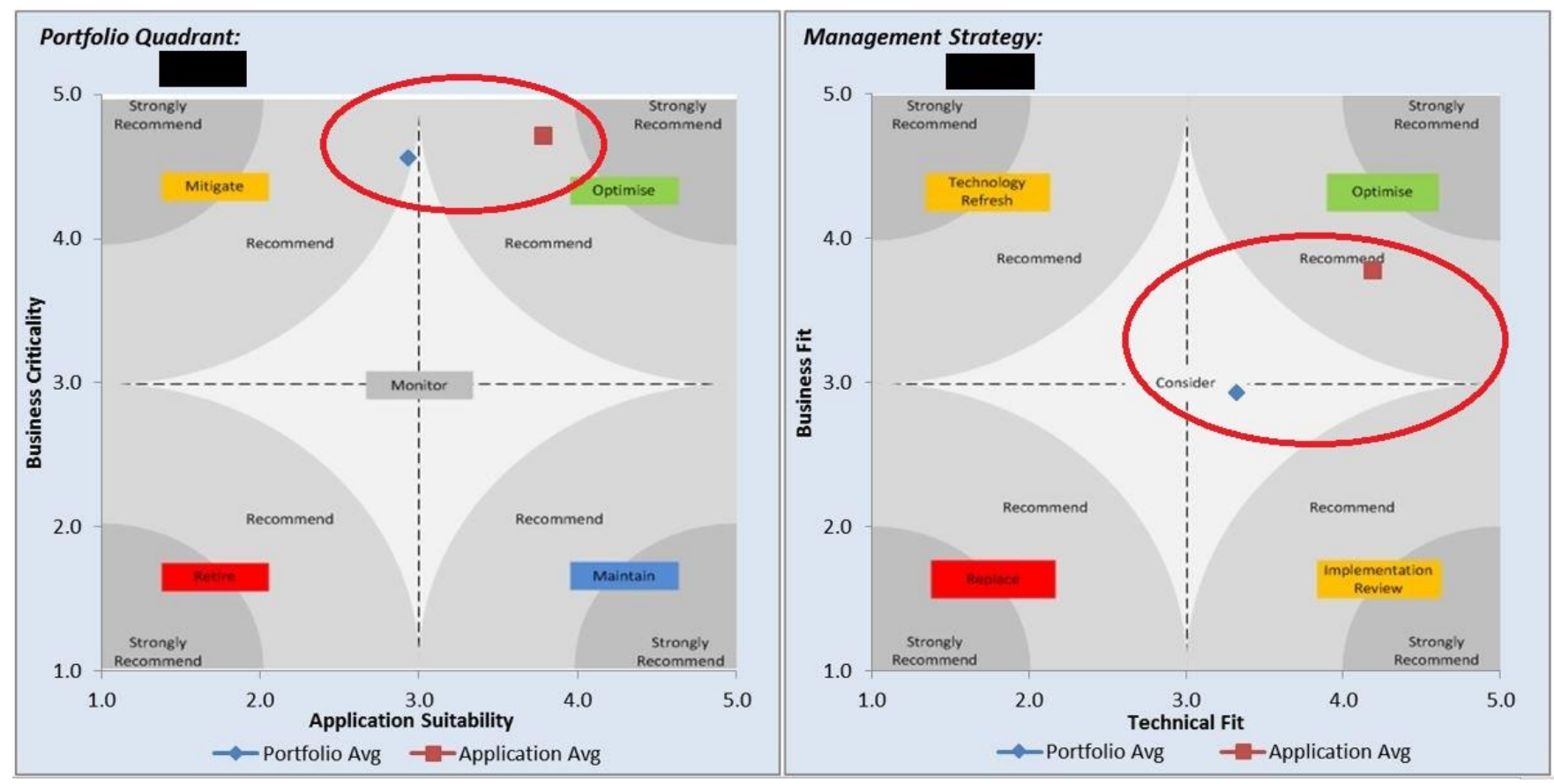

Figure 5. The remaining two graph types from the application maturity survey results, for a system [product name redacted] that is performing well. The specific system's location is shown by the red square, while the blue diamond maps the average for all systems in the application portfolio. Full size version available at https://doi.org/10.6084/m9.figshare.6667442.

Figures 6 and 7 present the same set of graphs for an end-of-life system.

In figure 6 the graph on the left shows that the product is very business-critical but that its scores for Technical Fit and Business Fit (the lower corners of the pink triangle) are lower than the average across all applications (the lower corners of the blue triangle). The graph on the right shows that Supportability and the Time to Market for changes and enhancements (the least prominent "points" in the pink polygon) are below the portfolio average (shown in blue along the same axes) while scores for other criticality, standards compliance, information quality, and performance were more in line with the portfolio average. 


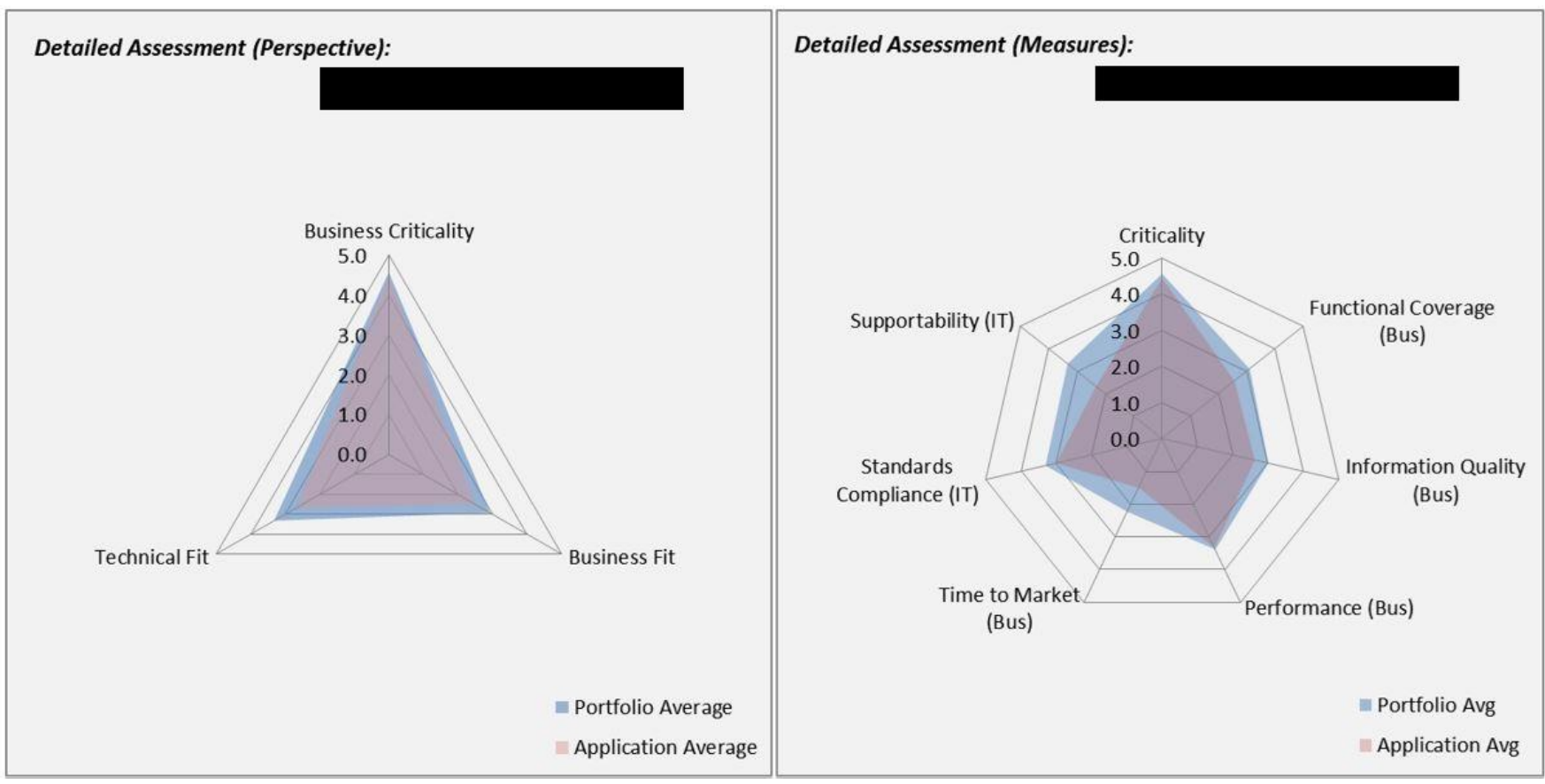

Figure 6. The first and second (of four) graphs for a system [product name redacted] that is endof-life. Full size version available at https://doi.org/10.6084/m9.figshare.6667478.

In figure 7, this application is placed well within the quadrant suggesting replacement.

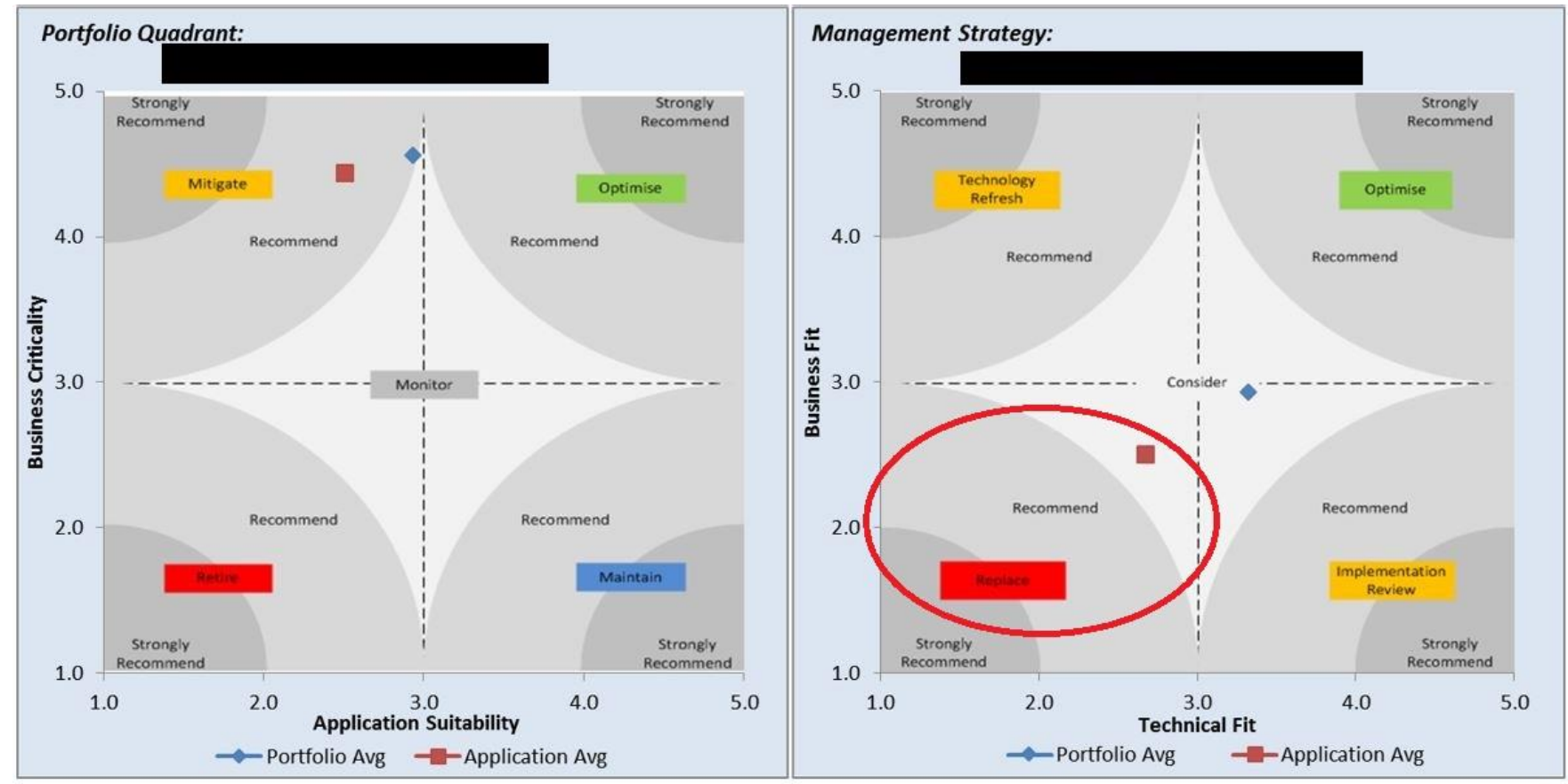

Figure 7. The third and final graphs for a system [product name redacted] that is end-of-life. The placement of the red square within the Replace quadrant indicates that this product is a high candidate for decommissioning. This is a marked difference from the portfolio as a whole (the blue diamond), which could be reviewed for possible implementation improvements. Full size version available at https://doi.org/10.6084/m9.figshare.6667484. 
The graphs are also useful for highlighting anomalies. Figure 8 shows a product that is assessed as better-than-average in the portfolio on most measures. However, the survey results quite clearly show that information quality is a major issue.

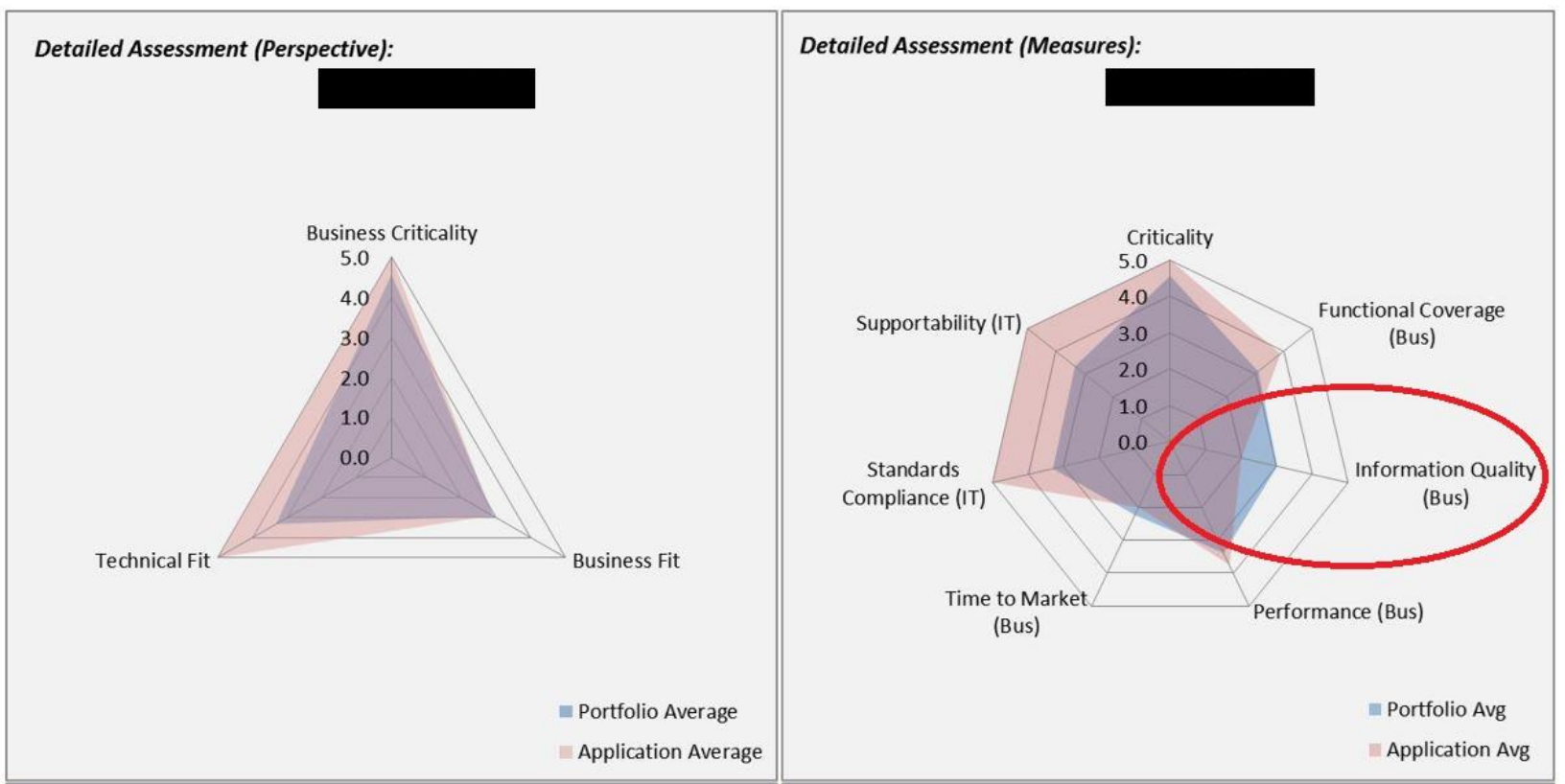

Figure 8. Graph from application maturity survey showing a specific area of concern (data quality) for an otherwise well-performing application [product name redacted]. Full size version available at https://doi.org/10.6084/m9.figshare.6667487.

This type of finding will help Library Technology Services to target our continuous improvement efforts and work through our relationships with user groups and vendors to get a better result.

\section{Application Communication Diagram}

The third major activity was the production of an application communication diagram (see figure 9). This is a visual representation of all of the information that was collated through the workshops using the workbook described above. 


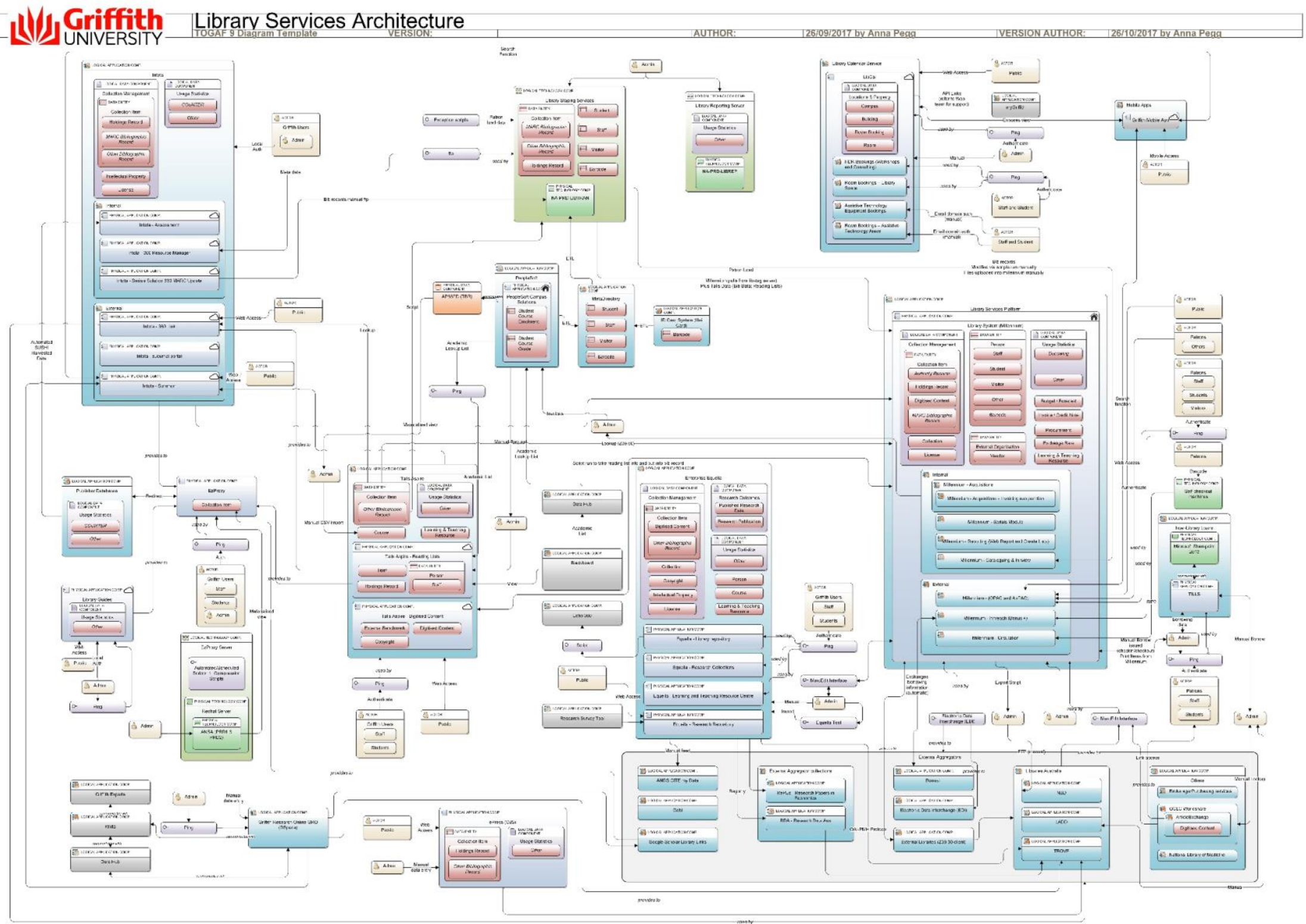

Figure 9. Application communication diagram [simplified view]. Full size version available at https://doi.org/10.6084/m9.figshare.6667490. 
The diagram includes a number of things to note.

- Key applications that make up the library ecosystem. An example of this is the large blue box on the top left. This represents the Intota product suite from ProQuest, which contains multiple components, including our link resolver, discovery layer, and electronic resource manager.

- Physical technology. Self-checkout machines appear as the small green box mid-right.

- Other internal systems that connect to library system components. Examples of these are throughout and include: corporate systems, such as PeopleSoft for human resources and finances; identity management systems like metadirectory and Ping Federate; the learning management system Blackboard; and research systems, including the research information management system and the researcher profiles system.

- External systems that connect to our systems. These are mostly gathered into the large grey box bottom right.

- Actors who access the systems. This includes administrators, staff, students, and the general public. Actors are identified using a small person icon.

- Interfaces between components. Each line in the diagram represents a unique connection into another system or interface. Captions on these lines indicate the nature of the connection, e.g. manual data entry, Z39.50 search, export scripts, and lookup lists.

The production of this diagram has been an iterative process that has taken place over a long time period. The number of components involved in the diagram is quite large, so it is worth noting that the version presented here has actually been simplified. The architects' tools can present information in different ways and this particular "view" was chosen to balance the need for detail and accuracy with the need to communicate meaningfully with a variety of stakeholders.

\section{Production of interactive visualizations}

In the fourth and final work package, the data entity and application inventory spreadsheet was used as a data source to provide an interactive visualization (see figure 10).

A member of the architecture team converted the workbook (see figure 2) from Microsoft Excel .xls into a .csv file. He developed a PHP script to query the file and return a JSON object based on the parameters that were passed. The Data Driven Documents JavaScript library (D3.js) was used to produce a force graph that uses shapes, colors, and lines to visually present the spreadsheet information in a more interactive way. ${ }^{18}$

This tool enables navigation through the Library's network of data entities (shown as orange squares) and applications (shown as blue dots). In the example being displayed, the data entity "Bibliographic records-MARC" has been selected. It is possible to see both in the visualization and in the popup box on the left how MARC records are captured, stored, and used across our entire ecosystem of applications.

This visualization was very much an experiment and the value of this in the long term is something we are still discussing. In the short term, other outputs have proven to be more useful for planning purposes. 


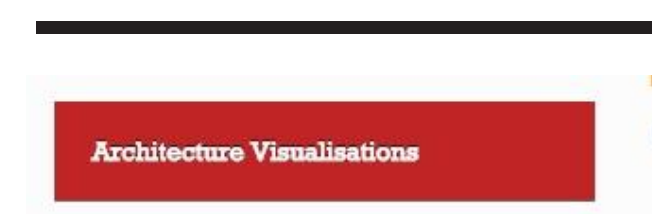

Mapping Applications (Physical to Logical)

Mapping data creators/ enters to consumers

\begin{tabular}{|c|}
\hline $\begin{array}{c}\text { Entity Collection Item(Bibliographic records - } \\
\text { MARC) }\end{array}$ \\
\hline * MarcEdit \\
\hline $\begin{array}{l}\text { RS External (Any Libraries with a Z39.50 } \\
\text { client) }\end{array}$ \\
\hline RS Intota - 360 Resource Manager \\
\hline RS Intota - SUMMON \\
\hline RS Libraries Australia \\
\hline RS Millennium - (OPAC and AirPAC) \\
\hline RS Millennium - Innreach (Bonus +) \\
\hline RS Talis Aspire - digitised content \\
\hline RS Talis Aspire - reading lists \\
\hline $\mathrm{SR}$ Electronic Data Interchange (EDI) \\
\hline $\mathrm{SR}$ Gobi \\
\hline SR Millennium - Acquisitions \\
\hline SR Millennium - Cataloguing \& Innview \\
\hline SR Millennium - Circulation \\
\hline
\end{tabular}

This graph links data entities to Library

systems/ applications that are used to enter the data, record the data and read the data. Data entities are orange squares, systems or applications are blue circles.

\section{SE: System of Entry (dashed line)}

SR: System of Record (solid line)

RS: Reference System (dotted line)
-

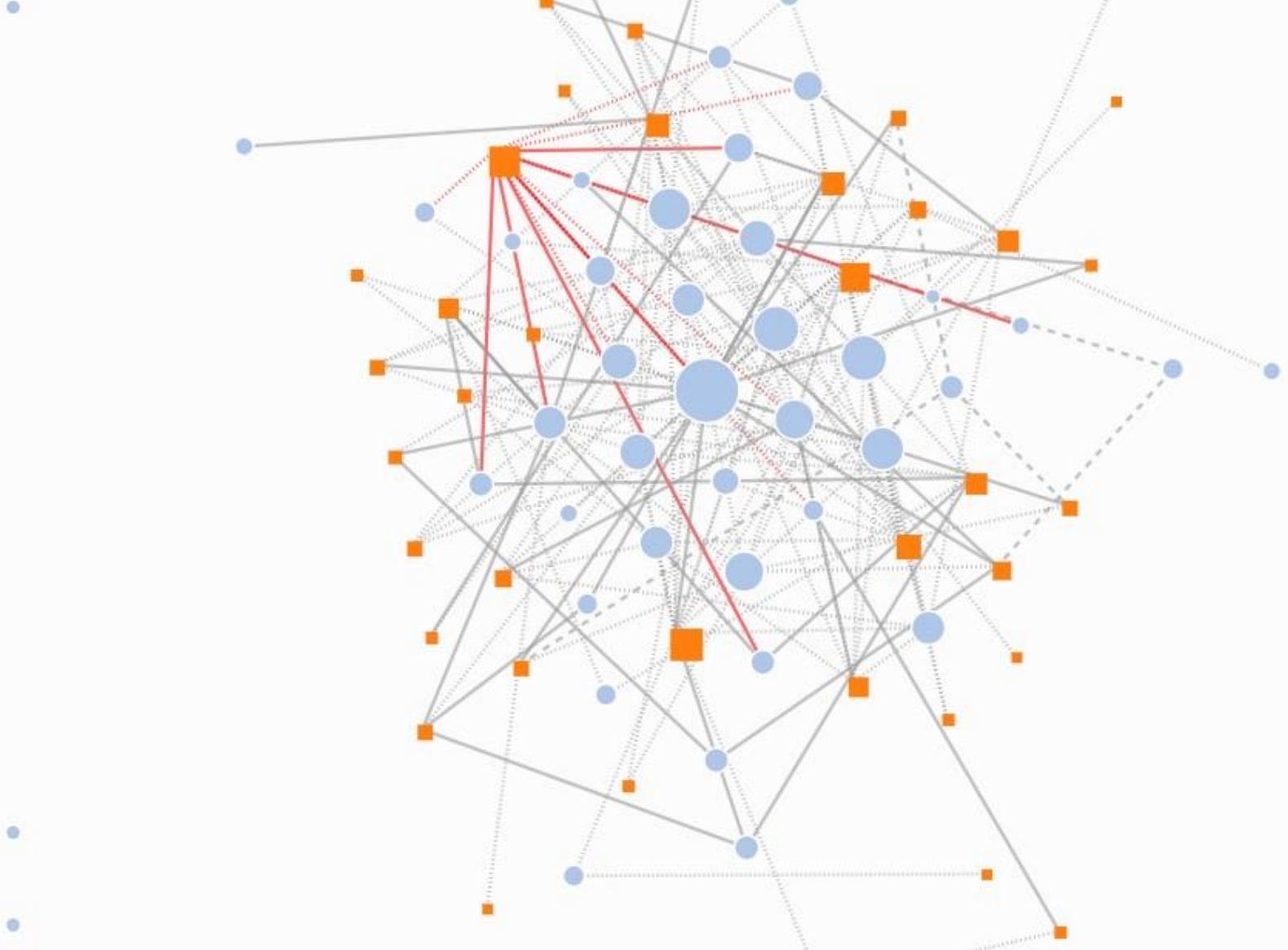

Figure 10. Interactive visualization of library architecture, showing relationships between a single data subentity (Bibliographic records_MARC) and various applications. Full size version available at https://doi.org/10.6084/m9.figshare.6667493. 


\section{DISCUSSION}

The process described above was not without its challenges, including establishing a common language. Enterprise architecture and libraries are both fertile breeding grounds for jargon and acronyms. There was also a disconnect in our understandings of who our users were, with the architects tending to concentrate on internal users, while the librarians were keen to include the perspectives of the academic staff and students who make up our core client base.

These were minor challenges, and the experience of working with the enterprise architects was overall an interesting and positive one for the Library. Our collaboration validated McKay and Parker's view that there is much crossover in the skillsets and mindsets of librarians and enterprise architects. ${ }^{19}$

Both groups tended to work in systematic and analytical ways, which was helpful in removing some of the more emotive aspects that might have arisen through a more judgmental "assessment" process. The enterprise architects' job was to promote conformance with standards that are aspirational in many respects for the Library. However, the collaborative nature of the process and the immediate usefulness of its outputs helped us to approach this as an opportunity to improve our internal practices as well as the services that we offer to library customers.

The architects observed in return that library staff were very open-minded about the process; this had not necessarily always been their experience with other groups in the University. One reason for this may have been LTS's efforts to communicate early with other library staff. Before embarking on this work, we sent emails and provided verbal updates to all participants and their supervisors. These communications were clear about both the time commitment needed for workshops and surveys and also about the benefits we hoped to achieve.

\section{Short-Term Impacts in the Library Domain}

The level of awareness and understanding in Library Technology Services about EA concepts and methods is much higher than what it was previously. Our capacity to self-identify architectural issues is better as a result and this is enabling us to be proactive rather than reactive. A recent example of this is a request from our Solution Architecture Board (SAB) to seek an exemption from our IT Advisory Board (ITAB) for our proposed use of the NISO Circulation Interchange Protocol (NCIP) to support interlibrary loan. While NCIP is a NISO standard that is widely used in libraries, it is not one of the integration mechanisms incorporated into the architecture standards. As a result of this request, we plan to develop a document for these IT governance groups about all the library-specific data transfer protocols that we use; not just NCIP, but also Z39.50, the Open Archives Initiative Protocol for Metadata Harvesting (OAI-PMH), the EDIFact standard for transferring purchasing information, and possibly others. It is in our interests to educate these important governance groups about integration methods commonly used in the library environment, since these are not well understood outside of our team.

The baseline as-is application architecture diagram gives us a much better grasp on the complexity we are faced with. Understanding this complexity is a prerequisite to controlling it. The diagram, and the process worked through to populate it, makes it easier to identify manual processes that should be automated and integrations that might be done more efficiently or effectively. For example, like most libraries, we still have many scheduled batch processes that we could potentially replace in the future with web services to provide real-time updates. 
The iServer platform is now an important source of data to support our decision-making, in terms of arriving at broad recommendations for replacing, reimplementing, or optimizing our systems as well as highlighting specific areas of concern. Importantly, the process produced relative results, so that we can see across our application portfolio which systems are underperforming compared to others. This makes it easier to determine where the team should be putting its efforts and highlights areas where firmer approaches to vendor management could be applied. A practical example of this was our decision in late 2017 to review (and ultimately unbundle and replace) an e-journal statistics module that was underperforming compared to other modules within the same suite.

The outputs from this process are also helping Library Technology Services communicate, both within our own team and also with other stakeholders. The results of the application maturity assessment were included as part of a business case seeking project funding to upgrade our library management system and replace our interlibrary loans system. That funding bid was successful. While it is possible that the business case would have been approved regardless, a recommendation from the architects that the system needed to be replaced was likely more persuasive than the same recommendation coming solely from a library perspective. In our organizational context, enterprise architects are trusted by very senior executives; they are perceived as neutral and objective, and the processes that they use are understood to be systematic and data-driven.

\section{Longer-Term Impacts in an Enterprise Context}

There are a number of longer-term impacts that may arise from this work. Seeing the Library's applications in a broader enterprise context is likely to lead to more questioning of the status quo and to a desire to investigate new ways to do things. In large organizations like universities, available enterprise systems can offer better functionality and more standardized ways of operating than library systems. Financial systems are an obvious example, as are business intelligence tools. The canned and custom reports and dashboards within library systems meet a narrow set of requirements, but do not compare well for increasingly complex analytics when compared to enterprise data warehousing, emerging "data lake" technologies for less structured data, and sophisticated reporting tools.

An enterprise approach also highlights where the same process is being done across different systems. For example, OAI-PMH harvesting is a feature of multiple systems at Griffith.

Traditionally each system provides its own feeds. Our data repository, publications repository, and researcher profile system all provide OAI-PMH harvesting endpoints for sending metadata to different aggregators. An alternative solution to explore could be to harvest all publications data from multiple systems into our corporate data warehouse (particularly if this evolved to provide more linked data functionality) and provide a single OAI-PMH endpoint that could then be managed as a single service.

The EA process has further raised our already high level of concern with the current library systems market. There has been a move in recent years towards larger, highly-integrated "black box" solutions. While there have been some moves towards openness, for example through the development of APIs, these are often rhetorical rather than practical. The pricing structures for products mean that we continue to pay for functionality that would not be required if we could integrate library applications with non-library enterprise tools in smarter ways. At Griffith, the 
products that scored most highly in our maturity assessment in terms of business and technical fit were the less expensive, lightweight, browser-based, cloud-native tools designed to do one or two things really well. This suggests that strategies around a more loosely coupled microservices approach, such as that being developed through the FOLIO open source library software initiative, will be worth exploring in future. ${ }^{20}$

\section{CONCLUSION}

There are few documented examples of librarians working closely with enterprise architects in higher education or elsewhere. The goal of this case study is to encourage other librarians to learn more about architects' work practices and to seek opportunities to apply EA methods in the library systems space for the benefit not just of the library but also for the organization as a whole.

As a single institution case study, the applicability of this work may be limited in other environments. Griffith has a long tradition of highly converged library and IT operations; other organizations may have more structural barriers to entry if the Library and IT areas are not as naturally cooperative.

A further obvious limitation relates to resourcing. The author of the CISTI case study cautions that getting started in EA can be complex and resource-intensive. Few libraries are likely to be in the position of CISTI in having dedicated library architects, so working with others will be required. In many universities, work of this nature is outsourced to specialist consultants because of a lack of in-house expertise. At Griffith University, we conducted this exercise entirely with in-house staff. A downside of this was that, despite our best efforts at the scoping stage, competing priorities in both areas meant that this work took far longer than we expected. In theory, external consultants could have guided the Library through similar activities to produce similar outputs, and probably in a shorter timeframe. However, we would observe that the process has been just as important as the outputs; the knowledge, skills, and relationships that have been built will continue into the future.

At CISTI, investments in EA were assessed by the library as justified by the improvements in technology capability, strategic planning, and services to library users. The Griffith experience validates this perspective. It is also important to note that EA work can and should be done in an iterative way. Our experience suggests that some outputs can be delivered earlier than others and useful insights can be gleaned even from drafts. Our local "ecosystem" of library applications, enterprise applications, and integrations between these different components must respond to changes in technologies; legal and regulatory frameworks; institutional policies and procedures; and other factors. It is therefore unrealistic to expect outputs from a process like this to remain current for long. Assuming that the Library's data and application architecture will always be a work-in-progress, it will continue to be worth the effort involved to build and maintain positive working relationships with the enterprise architects, who now have a deeper understanding of who we are and what we do.

\section{ACKNOWLEDGEMENTS}

Thank you to Anna Pegg, Associate IT Architect; Jolyon Suthers, Senior Enterprise Architect; Colin Morris, Solution Consultant; the Library Technology Services team; all our Library and Learning Services colleagues who participated in this initiative; and Joanna Richardson, Library Strategy 
Advisor, for support and feedback during the writing of this article. This work was previously presented at THETA (The Higher Education Technology Agenda) 2017, Auckland, New Zealand.

\section{REFERENCES}

${ }^{1}$ Griffith University, "Griffith Digital Strategy 2020," 2016, https://www.griffith.edu.au/ data/assets/pdf file/0026/365561/griffithuniversity-digitalstrategy.pdf.

${ }^{2}$ The Open Group, “TOGAF ${ }^{\circledR}$, an Open Group Standard," accessed June 4, 2018, http://www.opengroup.org/subjectareas/enterprise/togaf.

${ }^{3}$ Federation of Enterprise Architecture Professional Associations, "A Common Perspective on Enterprise Architecture," 2013, http://feapo.org/wp-content/uploads/2013/11/CommonPerspectives-on-Enterprise-Architecture-v15.pdf.

${ }^{4}$ Judith Pirani, "Manage Today's IT Complexities with an Enterprise Architecture Practice," EDUCAUSE Review, February 16, 2017, https://er.educause.edu/blogs/2017/2/managetodays-it-complexities-with-an-enterprise-architecture-practice.

${ }^{5}$ Stephen Kevin Anthony, "Implementing Service Oriented Architecture at the Canada Institute for Scientific and Technical Information," The Serials Librarian 55, no. 1-2 (July 3, 2008): 235-53, https://doi.org/10.1080/03615260801970907.

${ }^{6}$ Kristiina Hormia-Poutanen, "The Finnish National Digital Library: National Library of Finland developing a National Infrastructure in Collaboration with Libraries, Archives and Museums," accessed March 24, 2018, http://travesia.mcu.es/portalnb/ispui/bitstream/10421/6683/1/fndl.pdf.

${ }^{7}$ Karl W. Schornagel, "Information Technology Strategic Planning: A Well-Developed Framework Essential to Support the Library's and Future IT Needs. Report No. 2008-PA-105," May 2, 2009, https://web.archive.org/web/20090502092325/https://www.loc.gov/about/oig/reports/20 09/Final\%20IT\%20Strategic\%20Planning\%20Report\%20Mar\%202009.pdf.

${ }^{8}$ Joel Willemssen, "Information Technology: Library of Congress Needs to Implement Recommendations to Address Management," December 2, 2015, https://www.gao.gov/assets/680/673955.pdf.

${ }^{9}$ Rebecca Parker and Dana McKay, "It's the End of the World as We Know It ... or Is It? Looking Beyond the New Librarianship Paradigm," in Marketing and Outreach for the Academic Library, ed. Bradford Lee Eden (Lanham, MD: Rowman and Littlefield, 2016): 81-106.

${ }^{10}$ New South Wales State Archives and Records Authority, "Recordkeeping in Brief 59-An Introduction to Enterprise Architecture for Records Managers," 2011, https://web.archive.org/web/20120502184420/https://www.records.nsw.gov.au/recordkee ping/government-recordkeeping-manual/guidance/recordkeeping-in-brief/recordkeeping-inbrief-59-an-introduction-to-enterprise-architecture-for-records-managers.

${ }^{11}$ Anthony, "Implementing Service Oriented Architecture," 236-37. 
12 Jolyon Suthers, "Information and Technology Architecture," 2016, accessed April 6, 2018 https://www.caudit.edu.au/system/files/Media\%20library/Resources\%20and\%20Files/Com munities/Enterprise\%20Architecture/EA2016\%20Joylon\%20Suthers\%20CAUDIT\%20EA\%2 0Symposium\%202016\%20-\%20IT\%20Architecture\%20v2 0.pdf.

13 The Open Group, “TOGAF ${ }^{\circledR}$ 9.1,” 2011, 2018, http://pubs.opengroup.org/architecture/togaf9doc/arch/index.html: Part 1 Introduction Section 2: Core Concepts.

${ }^{14}$ Orbus Software, "iServer for Enterprise Architecture," accessed March 26, 2018, https://www.orbussoftware.com/enterprise-architecture/capabilities/.

15 EBSCO, “GOBI ${ }^{\circledR}, ”$ accessed June 5, 2018, https://gobi.ebsco.com/gobi.

${ }^{16}$ Google Scholar, "Google Scholar Support for Libraries," accessed June 5, 2018, https://scholar.google.com/intl/en/scholar/libraries.html.

${ }^{17}$ National Library of Australia, “Trove," accessed June 5, 2018, https://trove.nla.gov.au/; Australian National Data Service, "Research Data Australia," accessed June 5, 2018, https://researchdata.ands.org.au/.

${ }^{18}$ Mike Bostock, “D3.Js—Data-Driven Documents,” accessed April 3, 2018, https://d3js.org/.

19 Parker and McKay, "It's the End of the World," 88.

${ }^{20}$ Breeding, Marshall, “Five Key Technology Trends for 2018," Computers in Libraries, 37, no.10 (December 2017), http://www.infotoday.com/cilmag/dec17/Breeding--Five-Key-TechnologyTrends-for-2018.shtml. 